\title{
LA LEXICOGRAFÍA ACADÉMICA DE MEDIADOS DEL SIGLO XIX: EL AUMENTO DE VOCES EN LA NOVENA EDICIÓN DEL DRAE (1843)
}

\section{ACADEMIC LEXICOGRAPHY OF THE MID-NINETEENTH CENTURY: THE INCREASE IN LEMMAS IN THE NINTH EDITION OF THE DRAE (1843)}

\author{
Margarita Freixas Alás \\ Universitat Autònoma de Barcelona \\ Grupo de Lexicografía y Diacronía \\ Margarita.Freixas@uab.cat
}

Recibido: 05/12/2018

Aceptado: 14/02/2019

\section{Resumen}

A lo largo del siglo XIX el diccionario de la Real Academia Española se consolida como una obra de referencia en la historia de la lexicografía y en la historia de la lengua española en general. En constante revisión, cada edición incorpora cambios en el método empleado y en las informaciones que atesora. El estudio contrastivo de las ediciones del DRAE permite conocer el alcance de las correcciones y del aumento. En este artículo se examina, en concreto, la aportación realizada en el DRAE 1843. Por un lado, se analizan las novedades en el diseño de la obra a partir de datos procedentes de las Actas de las juntas de la Academia, de las Reglas de 1838 y del Prólogo al DRAE 1843. Por otro lado, se examinan las características del aumento a través de los lemas añadidos a la edición anterior, de 1837.

PALABRAS CLAVE: Lexicografía académica, S. XIX, DRAE 1843

\begin{abstract}
Throughout the nineteenth century the dictionary of the Real Academia Española consolidated as a reference work in the history of lexicography and in the history of the Spanish language in general. Under constant review, each edition incorporates changes in the lexicographical methodology employed and in its information. The contrastive study of the DRAE editions allows us to know the scope of the corrections made and of the volume's enlargement. This article specifically examines the contribution made in DRAE 1843. On the one hand, changes in the design of the work are analyzed though data from the Actas of the Academy, the Reglas of 1838 and the Prólogo to DRAE 1843. On the other hand, the characteristics of the enlargement are examined through the lemmas added to the previous edition, from 1837.

KEY WORDS: Academic lexicography, $19^{\text {th }}$ c., DRAE 1843
\end{abstract}

Para citar este artículo / To cite this article: Freixas Alás, Margarita (2019). La lexicografía académica de mediados del siglo XIX: el aumento de voces en la novena edición del DRAE (1843). Azorín, Dolores; Clavería, Gloria y Jiménez Ríos, Enrique (Eds.): ELUA: El diccionario de la Academia y su tiempo: lexicografia, lengua y sociedad en la primera mitad del siglo XIX, Anexo V, págs. 181-203.

Enlace/Link: http://dx.doi.org/10.14198/ELUA2019.ANEXO5.08

(c) BY-NC Este trabajo se publica bajo una licencia de Creative Commons Reconocimiento-NoComercial 4.0 Internacional 


\section{INTRODUCCIÓN}

Los diccionarios académicos constituyen desde sus orígenes un referente insoslayable para la historia de la lexicografía y, en general, para la historia de la lengua (Álvarez de Miranda 2001: 35). En el siglo XIX la lexicografía monolingüe no académica, que eclosiona con obras de notable calidad como el diccionario de Salvá, de 1846 (Azorín 1994-1995: 10-12 y Azorín 2000: 229-256), toma como referencia las ediciones del diccionario de la Real Academia Española, ya sea para emularlas ya sea para tratar de corregir o ampliar su contenido. Se constituyen en tesauros sometidos de forma muy intensa al examen y a la crítica constantes de su lemario, definiciones e informaciones ofrecidas sobre el uso de las voces (Jiménez Ríos 2013). El análisis del diccionario no se encuentra únicamente en obras eruditas, sino que se expresa, la mayor parte de las veces, en artículos publicados en la prensa periódica, lo que prueba el interés público por una obra que a lo largo de los siglos ha ido configurándose, para los hablantes del español, como un referente fundamental para el conocimiento del léxico.

Adentrarse en el estudio detenido de las diferencias existentes entre los contenidos de las distintas ediciones del diccionario de la Real Academia Española permite obtener un conocimiento muy valioso de las aportaciones de la corporación en cada obra lexicográfica publicada. El análisis filológico de las ediciones del DRAE, cercano a las labores propias de la crítica textual — cotejo de versiones, descripción del proceso de redacción y búsqueda de posibles fuentes empleadas-, ofrece la posibilidad no solo de conocer con detalle la evolución de la técnica lexicográfica de los académicos, sino que también aporta valiosos datos sobre cómo se produce la incorporación y la supresión de léxico definido. Respecto a los diccionarios académicos de la primera mitad del siglo XIX, se encuentran en estudios recientes minuciosos trabajos en torno a las ediciones del DRAE 1817 (recogidos en Clavería/Freixas 2018a) del DRAE 1822 (Terrón en prensa) y del DRAE 1832 (Carriet en prensa).

La presente contribución tiene como objetivo acercarse al examen de las aportaciones de la novena edición del Diccionario de la lengua española, publicado por la Real Academia Española en 1843, tanto en lo que se refiere a las novedades en el diseño de la obra como en los cambios que experimenta el lemario por la adición de voces. Para ello, recurriré, por un lado, a la información contenida en las Actas, donde se resume el contenido de las sesiones de trabajo de los académicos, y al análisis del Prólogo del Diccionario y, por otro, al estudio de las entradas lexicográficas que se añaden respecto a la edición anterior de $1837^{1}$.

\section{LA ELABORACIÓN DEL DICCIONARIO DE 1843: EL MÉTODO DE TRABAJO}

La lectura de los resúmenes de las juntas de la Corporación facilita información valiosa sobre el proceso de revisión y de aumento al que fue sometida la octava edición del Diccionario de la lengua castellana hasta configurar los materiales impresos como novena edición. Desde

\footnotetext{
1 En este trabajo se parte de la metodología de análisis establecida en el proyecto de investigación "Historia interna del Diccionario de la lengua castellana de la Real Academia Española en el siglo XIX (1817-1852)", dirigido por Gloria Clavería (núm. de referencia FFI2014-51904-P), cuya financiación, junto al apoyo de la Generalitat de Catalunya para el Grupo de Investigación Consolidado "Grup de Lexicografia i Diacronia" (núm. de referencia 2017 SGR 1251), ha hecho posible las investigaciones realizadas para su consecución. Se ha contado con los datos

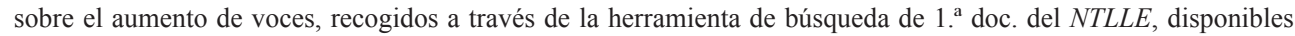
en la web del grupo de investigación, en la sección Lemateca, <https://draesxix.wixsite.com/draesxix/lemateca $>$.
} 
la distribución de los primeros ejemplares de la octava edición en agosto de 1837 hasta que terminaron las labores de revisión de los últimos materiales de la novena edición, los trabajos lexicográficos de la Real Academia Española se concentraron en dos obras: por un lado, en el aumento y revisión del Diccionario de autoridades, en concreto, en las entradas de las letras $R$ y $S$ (Clavería 2016: 114), y, a partir del 27 de febrero de 1840, en "los trabajos para la próxima edicción [sic] del diccionario", la novena, que terminaron el 14 de septiembre de 1843 con el "examen de algunos artículos para el Suplemento". Las labores dedicadas al Diccionario de autoridades, cuya influencia en el diccionario manual ha sido subrayada por diversos estudiosos de la lexicografía académica (Seco 1991; Clavería 2016: 114) ${ }^{2}$, dieron como fruto no solo el avance en la corrección y propuesta de aumento de entradas, sino también la impresión en 1838 de unas Reglas para la corrección y aumento del diccionario (Madrid, Imprenta Nacional $)^{3}$, cuyas novedades analizaremos en el apartado siguiente junto con la información que sobre el método lexicográfico ofrece el Prólogo al DRAE 1843.

Con anterioridad a la lectura y revisión sistemática de las entradas del $D R A E 1837$, con el fin de preparar la próxima edición del Diccionario, los académicos trabajaron en la revisión de "una lista de voces nuevas remitida por don Gregorio García del Pozo" (Actas, 9/VIII/1838). A pesar de que las Actas de la Academia no ofrezcan pistas que permitan identificar con seguridad la identidad de García del Pozo, es probable que se trate del ortógrafo y ortólogo que unos años más tarde dedicaría una obra (García del Pozo 1854) al análisis de los errores ortográficos de las ediciones novena y décima del DRAE (1843 y 1852) y de las erratas del Prontuario de ortografía de la lengua española (RAE, 1854, 5. ${ }^{\mathrm{a}}$ ed.), con especial atención a la denuncia de las erratas en las correspondencias latinas (Jiménez Ríos 2013: 151).

Las Actas no transcriben de forma completa la lista de García del Pozo, sino que únicamente informan de la última palabra del conjunto de voces examinado en las sesiones académicas comprendidas entre el 9 de agosto de 1838 hasta el 16 de mayo de 1839. El trabajo en torno a los materiales aportados se organiza en dos fases: una primera dedicada a la lectura de las voces, en las juntas celebradas entre el 9 de agosto de 1838 hasta el 29 de noviembre de 1838 , y una segunda centrada en su definición, proceso que da comienzo el 29 de noviembre de 1838 y que se concluye el 16 de mayo de 1839. Más adelante, el 28 de abril de 1842, también se informa de que se "empezó el examen de una lista de voces de don Gregorio García del Pozo, hasta afelpar"4. Estos datos extraídos de las Actas demuestran la pervivencia del método de trabajo tradicional desde la elaboración del Diccionario de autoridades y que consistía en una primera lectura de listados de voces que se sometían a aprobación y una segunda lectura de las definiciones ( $c f$. Freixas 2006 y Freixas 2010 sobre el Diccionario de autoridades) 5 .

2 Hasta tal punto se influenciaron mutuamente los dos proyectos lexicográficos de la Real Academia Española que, como demuestra Clavería (2016: 114), el Diccionario usual o chico, según solían llamarlo, llegó a tomarse como material de partida para los trabajos de ampliación y de enmienda del Diccionario de autoridades o grande. Así pues, a mediados de junio de 1837, "se acordó hacer un repartimiento con arreglo a la edición que se está imprimiendo del Diccionario chico, a fin de que cada individuo examine y corrija la parte relativa a las autoridades" (Actas, 15/06/1837, cit. en Clavería 2016: 114).

3 La publicación de las Reglas de 1838 vino motivada por la petición del Director en la junta del 31 de mayo de 1838 , que "hizo presente que habiéndose concluido los ejemplares del cuaderno que contiene las reglas para la corrección del Diccionario convendría reimprimirlas, y la Academia lo acordó así, determinando se tiren 200 ejemplares" (Actas).

4 No es posible determinar si se trata de la misma lista trabajada ya entre 1838 y 1839 o de una nueva lista.

5 Véase en el apartado $\S 4$ de la presente contribución, dedicado al análisis del aumento en el $D R A E 1843$, las voces de García del Pozo mencionadas en las Actas. 
La revisión sistemática de las entradas impresas en la octava edición del DRAE 1837 no da comienzo hasta el 27 de febrero de 1840, sesión en la que, tal y como se recoge en las Actas, se procedió al reparto de encargos entre los académicos que debían ocuparse de la corrección y aumento de partes del Diccionario. En concreto, se decidió reservar "para la lectura en sus juntas ordinarias los tres primeros cuadernos de la octava impresión" y el resto se repartió de manera que cada académico implicado tenía que ocuparse de la revisión de las entradas de un cuaderno. Cada cuaderno se componía de cuatro pliegos ${ }^{6}$ de diez páginas, por lo que cada encargo consistía en la enmienda de cuarenta páginas del diccionario, excepto el encargo del Director, al que correspondieron treinta y cinco páginas. En la lista del reparto (tabla 1) consta el nombre del académico responsable y la indicación del primer y del último lema de cada cuaderno:
Al S.r Mesonero desde Bordoncico hasta Cartela
Al S. ${ }^{r}$ Roca desde Cartelear hasta Consejo
Al S. ${ }^{\mathrm{r}}$ Gil desde Consejuela hasta Danzar
Al S. ${ }^{\text {r Seoane desde Danzarin }}$ h. ${ }^{\text {ta }}$ Diminucion
Al S. ${ }^{r}$ Cabo Reluz desde Diminuecer $\mathrm{h} .{ }^{\text {ta }}$ Equiponderar
Al S. ${ }^{r}$ Bigueral desde Equis h. ${ }^{\text {ta }}$ Floreta

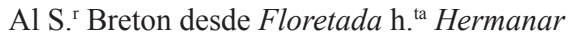
Al S. ${ }^{\mathrm{r}}$ Campo desde Hermanazgo h. $^{\text {ta }}$ Junto
Al S. ${ }^{\mathrm{r}}$ Revilla desde Juntorio h. $^{\text {ta }}$ Mariposa
Al S. ${ }^{r}$ Valle desde Mariposella h. $^{\text {ta }}$ Nona
Al S. ${ }^{\mathrm{r}}$ Lopez desde Nonada h. ${ }^{\text {ta }}$ Poner
Al S. ${ }^{r}$ Castillo desde Poniente h. ${ }^{\text {ta }}$ Recambio
Al S. ${ }^{\mathrm{r}}$ Duaso desde Recanvio $[$ sic $]$ h. ${ }^{\text {ta }}$ Saltar
Al S. ${ }^{r}$ Arano desde Saltaregla hasta Tardar
Al S. ${ }^{r}$ Navarrete desde Tarde [hasta] Vagamundear
Al S. ${ }^{\mathrm{r}}$ Director desde Vagamundo hasta el fin

Tabla 1. Reparto de los cuadernos del DRAE 1837 (Actas, 27/II/1840).

Las Actas informan de que el 7 de septiembre de 1843 terminó "la lectura de la lista de voces para el Diccionario". El 14 de septiembre de 1843 se "continuó el examen de algunos artículos para el Suplemento" y el 16 de noviembre de 1843 se señalaba que se habían regalado a la reina dos ejemplares de la novena edición. En definitiva, se invirtieron cuarenta y cuatro meses, un poco más de tres años, para la revisión del Diccionario usual, cuyas directrices examinaremos a continuación mediante el análisis de las cuestiones referidas al aumento en las Reglas de 1838 y en el Prólogo al DRAE 1843.

\section{LOS PRINCIPIOS DEL DICCIONARIO DE 1843: LAS REGLAS DE 1838 Y EL PRÓLOGO}

Las Reglas de 1838 reúnen los acuerdos que se habían ido tomando respecto a la manera en la que debía recogerse y redactarse la información lexicográfica en los diccionarios

6 Tal y como recoge el DRAE 1837 en la tercera acepción de cuaderno, "En la imprenta es el compuesto de cuatro pliegos metidos uno dentro de otro". 
académicos en relación con la voz, el 'lema'; la calidad, 'categoría gramatical'; la definición o explicación de las voces; la correspondencia latina; la autoridad, cuya información no se ofrece en el Diccionario usual; y la colocación, orden de los elementos que componen el repertorio lexicográfico ${ }^{7}$. Junto a las Reglas se publicó una "Adición que se hizo a estas reglas por acuerdo de la Academia en 26 de febrero, y 3 de marzo de 1818" (Reglas 1838: 26-32) que trata sobre cómo realizar el vaciado de las autoridades. Una de las observaciones incluidas en la "Adición..." demuestra también la relación existente entre los dos proyectos lexicográficos que la Real Academia Española realizaba en paralelo: el Diccionario de autoridades y el Diccionario usual $^{8}$. En el apartado $\S 7$ se expone de forma explícita cómo se complementaban los materiales de ambas obras:

Luego que el académico reciba el aviso del repartimiento que le ha tocado ó corresponda, y las cédulas de aumento y correccion que se le entreguen, tratará de coordinarlas y confrontarlas con los artículos del Diccionario pequeño de la última edicion, para examinar las que son de aumento, é intercalarlas en sus lugares respectivos, y las que fueren de correccion para enmendar con este conocimiento los artículos diminutos ó defectuosos (Reglas 1838: 30).

Tal y como han señalado Rodríguez y Garriga (2010: 48) y Clavería (2016: 114), las Reglas de 1838 no suponen una transformación radical de las últimas directrices publicadas hasta la fecha (Reglas 1760/1770). Incluyen los acuerdos que entre 1770 y 1838 fueron aprobándose en las juntas académicas con relación a algunos aspectos de la redacción de las entradas lexicográficas. Con respecto al aumento, objeto de estudio de esta contribución, destaca la ausencia de menciones al tratamiento que debe darse a las voces de origen extranjero, cuestión que se tratará en el Prólogo del DRAE 1843. No se recuperan, por lo tanto, las consideraciones que sobre los préstamos se habían incluido en las Reglas desde 1743 hasta 1764 :

Se pondrán asimismo las voces tomadas modernamente de otros idiomas, si han llegado á ser de uso comun, no obstante que haya otras equivalentes en Castellano, lo que se deberá prevenir en el mismo artículo (Reglas 1764: 16).

En cambio, en las "Adiciones" a las Reglas de 1838 se incluyó una interesante observación sobre la necesidad de incorporar voces procedentes de las ciencias y de las artes a través de los usos de este tipo de léxico en obras de especialidad:

Las autoridades de voces facultativas se tomarán de los mejores autores del arte ó facultad respectiva, como para las de mineralogía y metalurgia de Vargas en su tratado de $R e$ metálica, de Barba en su arte de los metales, \&c.: las de agricultura de Herrera, Gregorio de los Ríos, \&c.: las de marina de Martín Cortés, Pedro de Medina, Tomé Cano, \&c.;

7 En este apartado se encuentran observaciones sobre aspectos variados: el orden alfabético de los lemas; el orden de los sinónimos en las definiciones compuestas por más de uno; la lematización de las frases, las 'unidades fraseológicas'; el lugar de las acotaciones de uso para indicar "ser una voz peculiar de alguna ciencia, arte ó provincia"; y otras consideraciones no relacionadas con la ordenación: las remisiones, las propuestas dirigidas a corregir la lista de abreviaturas y a elaborar una lista de autores, el método de revisión del diccionario, y, por último, la necesidad de tener "arreglada y corregida la ortografía".

8 No se publican unas Reglas específicas para el Diccionario usual y desligadas de los trabajos del Diccionario de autoridades hasta 1869 y 1870, "años en que se publican sendos folletos cuyo título es ahora, significativamente, Reglas para la corrección y aumento del diccionario vulgar" (Álvarez de Miranda 2001: 50). 
y las militares de Diego de Álava, Don Carlos Coloma, Don Bernardino de Mendoza y otros de esta clase (Reglas 1838: 28).

En definitiva, se reconocía de forma explícita la importancia de los tratados de especialidad como fuente para la información del Diccionario. Desde la primera edición del Diccionario de autoridades (1726-1739) y en todas las ediciones del Diccionario usual, fue una práctica habitual extraer de los tratados de especialidad no solo los lemas de las voces facultativas, sino también informaciones con las que se redactaban las definiciones ${ }^{9}$.

En el Prólogo al DRAE 1843 las consideraciones sobre el aumento del Diccionario son mucho más extensas y detenidas que las que se encuentran en las Reglas de 1838. De hecho, los preliminares se constituyen en una defensa de la selección léxica realizada en el Diccionario por la Corporación en torno a dos cuestiones fundamentales: los neologismos y el lenguaje de especialidad. En ambos casos, la Real Academia Española se defiende de las críticas de quienes "infieren que el Diccionario está diminuto" por faltar en él palabras de uso reciente o voces facultativas (DRAE 1843: Prólogo).

Respecto a los extranjerismos, se sostiene un criterio restrictivo ${ }^{10}$, de manera que la Corporación se justifica ante quienes se lamentan por no encontrar en el diccionario préstamos de reciente circulación en las publicaciones periódicas (Alvar Ezquerra 1983: 210):

Este es el objeto primordial del Diccionario, dar á conocer las palabras propias y adoptivas de la lengua castellana, sancionadas por el uso de los buenos escritores; pero muchos no lo entienden así; y cuando no encuentran en el Diccionario una voz que les es desconocida, en vez de inferir que no es legítima y de buena ley, lo que infieren es que el Diccionario está diminuto. Así hemos visto lamentarse algunos de no hallar en él las palabras comité (por comision), secundar (por cooperar), y otras muchas extranjeras de que están infestados la mayor parte de los escritos que diariamente circulan y que todo el mundo lee por la importancia de los asuntos sobre que versan.

No obstante, como señaló Alvar Ezquerra (1992: 55), “comité, secundar entraron en el Diccionario cuando la necesidad y el uso lo exigieron"; en el DRAE 1914 se introdujo la voz comité; y secundar, en el DRAE 1869. Asimismo, el uso acabó provocando la entrada en el Diccionario de palabras relacionadas con las modas y costumbres - "casi siempre de origen y estructura extranjera" (DRAE 1843: Prólogo) — que la Academia, en principio, también había descartado como lemas por la probabilidad de que se emplearan de forma pasajera ${ }^{11}$ :

Hay sin embargo en el lenguaje social voces de uso corriente, que por designar objetos frívolos, transitorios y casi siempre de origen y estructura extranjera no deben tener entrada en el Diccionario de una lengua, y si bien no faltan en el nuestro vocablos de esta clase pertenecientes á tiempos pasados, la Academia está persuadida de que no deben admitirse. Tales son los que se refieren á objetos de modas pasajeras y fugaces, como canesús,

9 Véase en Clavería/Freixas (2018) el procedimiento empleado en el DRAE 1817.

10 En el DRAE 1843 es ocasional la incorporación de préstamos como esplin, "Humor tétrico que produce tedio de la vida. Es voz tomada del inglés", voz con una amplia documentación en la literatura de los siglos XVIII y XIX, con ejemplos en el CORDE en las obras de Leandro Fernández de Moratín, Manuel Bretón de los Herreros y Ramón de Campoamor, entre otros.

11 Este criterio se había enunciado ya de forma similar en el Prólogo al DRAE 1832: “Así que [la Academia] ha excluido los nombres caprichosos y pasageros de trajes y modas que hoy se emplean y mañana desaparecen para no volverse á oir nunca". 
bandolina, capotas y otros á este tenor que nacen hoy y mueren mañana sin dejar mas vestigios que la burla que de ellos suele hacer para diversion del público algun festivo escritor satirico ó dramático (DRAE 1843: Prólogo).

Así, en la siguiente edición, la décima, se introdujo una nueva acepción para capota, referida al "adorno que usan las damas, mas ligero y de menos lujo que el sombrero, aunque muy semejante en la forma" (DRAE 1852), seguida de la observación "es voz de uso moderno", que claramente indica la conciencia de que se trataba de un neologismo. Y en la undécima edición, DRAE 1869, ya se dio cabida en el lemario a canesú, "cuerpo de vestido corto de mujer y sin mangas", y a bandolina, "cocimiento de zaragatona, de goma tragacanta, de pepitas de membrillo, ó de otras sustancias, al cual se echa siempre agua de colonia, y que sirve para mantener asentado el pelo despues de atusado".

De forma más extensa que en el caso de los extranjerismos y de las voces referidas a "modas pasajeras y fugaces" se trata sobre los "términos facultativos pertenecientes á las artes y las ciencias" (DRAE 1843, Prólogo) en los preliminares de la novena edición del Diccionario académico, recogiendo y ampliando aspectos mencionados en los prólogos de los diccionarios anteriores (Alvar Ezquerra 1983: 210). El interés por defender los criterios de selección léxica pudo estar motivado por las críticas que la Real Academia Española recibió al respecto (Jiménez de los Ríos 2013; Clavería 2016). En particular, la Academia se refiere a "ciertas observaciones amistosas y urbanas de una respetable e ilustrada corporacion" (DRAE 1843: Prólogo), no identificada ${ }^{12}$, aunque, como ya se ha señalado (Clavería 2016: 119-120), en la redacción de los preliminares del DRAE 1843 pudieron influir también las críticas que recibió la Corporación a raíz de la publicación del Panléxico, obra de Juan Peñalver impresa a partir de $1842^{13}$. El diccionario de Peñalver (1842) atacaba el método lexicográfico colegiado de la Real Academia Española ${ }^{14}$, especialmente en lo que se refería a la definición, y se presentaba desde el título - Panléxico, diccionario universal de la lengua castellana - como un diccionario universal, cuyos ambiciosos objetivos en cuanto a la nomenclatura se resumían en el Prólogo aludiendo a que se pretendía

No solo hacer un diccionario de la lengua castellana, sino formar un tratado que resuelva todas las dificultades que pueden ocurrir sobre el lenguaje, es decir, sobre la casi totalidad de los conocimientos humanos (Peñalver 1842: Prólogo).

Esta concepción del Diccionario como un tesoro en el que debería reunirse la nomenclatura de "la casi totalidad de los conocimientos humanos" se oponía radicalmente

12 Tampoco una lectura atenta de las Actas entre 1837 y 1843, donde se encuentran distintas menciones a las relaciones de la Real Academia Española con otras instituciones, "la Academia de Buenas Letras de Barcelona, la Academia de Ciencias Naturales, la Academia Grecolatina, la Academia Sevillana de Buenas Letras, el Ateneo Científico y la Academia Alemana-Española" (Clavería 2016: 121), descubre a qué corporación puede hacer referencia.

13 La polémica entre el editor del Panléxico, Ignacio Boix, y el Secretario de la Real Academia Española, Juan Nicaso Gallego, en diversos artículos publicados en la Gaceta de Madrid en septiembre de 1842 recoge el desagrado con que la Corporación recibió la publicación de esta obra (Clavería 2016: 121-122). Cf. también las Actas del 8 de septiembre de 1842 .

14 San Vicente (2010) subraya la defensa del método colegiado en lo que se refiere a los términos de especialidad en el Prólogo al DRAE 1843, donde la actividad de la Real Academia Española se equipara a la realizada por otros colectivos de prestigio, como l'Académie Française y La Crusca. 
a la que tenía la Real Academia Española de su Diccionario usual, ya que si la "inmensa nomenclatura de las ciencias, artes y profesiones" debiera "formar parte del Diccionario de la lengua comun, lejos de ser un libro manual y de moderado precio, circunstancias que constituyen su principal utilidad, sería una obra voluminosa en demasía, semi-enciclopédica y de difícil adquisición y manejo" (DRAE 1843: Prólogo). Tal y como señalaba en su discurso de ingreso el académico Daniel de Cortázar, sobre "algunas ideas referentes a los neologismos" (23 de abril de 1899), la edición del DRAE 1843 "manifestaba la resistencia que [la Corporación] seguía oponiendo á la admisión en el Léxico de voces nuevas ó privativas en su origen de las ciencias y de las artes" (Cortázar, 1899: 33). En este sentido, las afirmaciones del DRAE 1843 sobre el léxico facultativo amplían e ilustran el criterio de selección restrictivo ya enunciado desde el Prólogo a la segunda edición del Diccionario de autoridades (1770):

De las voces de ciencias, artes y oficios solo se ponen aquellas que están recibidas en el uso comun de la lengua, sin embargo de que la Academia pensó antes ponerlas todas, y para esto hizo repartimiento de ellas entre los Académicos, como se previno en el sexto tomo de la primera edicion. La razon de haber variado consiste, en que este no es un Diccionario universal pues aunque se propuso hacerle copioso y esto se ha procurado, se debe entender de todas las voces que se usan en el trato ó comercio comun de las gentes, y así no deben entrar en él las de ciencias, artes, y oficios que no han salido del uso peculiar de sus profesores (Diccionario de autoridades 1770: Prólogo).

En el DRAE 1843, no obstante, se desarrollan estas observaciones mediante una exposición detallada del método empleado para distinguir las voces de las artes, ciencias y oficios que pertenecen al uso común de aquellos tecnicismos restringidos a las manifestaciones lingüísticas propias de especialistas. El oficio de los académicos consiste en "ir notando gradualmente los progresos de la lengua, y apuntando, como un cronista, las innovaciones que introduce y generaliza el uso de las gentes instruidas y en particular en de los escritores que procuran explicarse con propiedad y pureza" (DRAE 1843: Prólogo). De este modo, las palabras relacionadas con las artes, las ciencias o los oficios merecen entrar como lemas en el Diccionario únicamente cuando se demuestra su uso en textos no especializados en los ámbitos de conocimiento a los que pertenecen:

Cuando en una obra histórica, en una disertacion legal, en una novela, en una arenga parlamentaria, en un tratado de Economía o de materias filosóficas ó morales, se emplean oportunamente los términos anatómicos tráquea, pulmon, espina dorsal, ó bien las voces radio, diámetro, ó círculo, propias de la Geometria, ó se habla del cáliz de una flor, ó se nombra la jarcia, la quilla ó la proa de un navío, nadie tachará el uso de tales palabras, supuesta la conveniencia de su aplicacion. Pero ¿quién no se burlaria del que en semejantes escritos sacase á colacion el coccix ó las vértebras cervicales; los catetos ó la ciclóide, ó bien el tallo de los monocotiledones ó el cáliz de cuatro lacinias? Tales vocablos son tan desconocidos oara la generalidad de las gentes, que no pueden salir de las obras técnicas á que pertenecen, y en ellas es donde deben buscar los curiosos su significado. Tal vez llegará tiempo en que se hagan familiares y el uso comun los prohije. Entonces tendrán derecho á entrar en el Diccionario, y podrá cualquiera servirse de ellos en la conversacion y en sus escritos sin nota de afectacion ó pedanteria (DRAE 1843: Prólogo). 
Sin embargo, tal y como ya se ha señalado anteriormente, recuérdese que, a pesar de las restricciones expuestas en el Prólogo en cuanto a la selección léxica, según las Reglas de 1838 los "mejores autores del arte ó facultad respectiva" eran los que debían sustentar el uso de las voces facultativas seleccionadas, de manera que la consulta de tratados de especialidad no quedaba excluida como fuente del Diccionario, en el que se reconoce que tenían cabida "muchos vocablos técnicos de Náutica, de Blason, de Esgrima, \&c, que no debieran estar en él, y solo conserva por respeto á su posesion y á la memoria de nuestros predecesores" (DRAE 1843: Prólogo) ${ }^{15}$.

Tras el DRAE 1843, y tal y como señala Daniel de Cortázar (1899) y los estudios recientes sobre el DRAE 1899 (Clavería 2003: 293-296), la décima edición, de 1852, supuso un primer paso hacia un criterio más amplio respecto a la aceptación de voces facultativas:

El mayor número de vocablos ahora agregados procede, ya de las novedades que se han ido experimentando en todos los ramos de la administración pública por consecuencia de las actuales instituciones políticas, ya del rápido vuelo que á su sombra tutelar han tomado las artes, el comercio y la industria (DRAE 1852: Prólogo).

Prueba de la progresiva apertura hacia la inclusión del léxico de especialidad es el hecho de que en la última edición del diccionario académico en el siglo XIX ya se había dado entrada como lemas a todas las palabras rechazas en el Prólogo al DRAE 1843. Así, coccix se incorporó en el DRAE 1899; las vértebras cervicales, s. v. cervical en el Suplemento al $D R A E 1899$ (y, con anterioridad, aparecían ya en la definición de vértebra del DRAE 1869); cateto, en el DRAE 1884; cicloide, en el DRAE 1817; monocotiledón, en el DRAE 1899; y lacinia, en el DRAE 1884. La incorporación de estas voces en el diccionario académico no puede atribuirse únicamente a que algunas de ellas pudieran acabar por "vulgarizarse" (DRAE 1843: Prólogo), pues este proceso no se dio para voces como monocotiledón, sin ninguna documentación en un amplio corpus de textos como el CREA. En la entrada de estas palabras influyó, sin duda, la aplicación de criterios de selección cada vez menos restrictivos en lo que se refería a las voces de especialidad, de manera que Diego de Cortázar, a punto de la publicación del DRAE 1899, consideraba que:

Siguiendo el camino emprendido, dentro de poco tiempo nuestro Diccionario estará á la cabeza del movimiento lexicográfico moderno, y las voces que sean indispensables para expresar las necesidades progresivas de las ciencias y de las costumbres quedarán aceptadas, con toda la autoridad y prestigio necesarios (Cortázar 1899: 38).

El DRAE 1843 prefería, en cambio, declinar la copia de las ciencias modernas y de los “oficios y artes industriales complicadísimas", que no podría abarcar:

Si el naturalista se quejase de no encontrar en él las voces todas con que de dia en dia se va aumentando el caudal de su profesion predilecta, con igual motivo se quejaría el astrónomo, el químico, el anatómico, el farmacéutico, el veterinario, y en suma los aficionados á cuantos ramos del saber componen hoy el inmenso tesoro de los conocimien-

15 Más adelante, Salvá (1846) revisaría los criterios de selección de las voces facultativas criticando a la Real Academia Española por la excesiva representación de algunas áreas de especialidad en su Diccionario (Azorín 2002; Clavería 2016: 118-119). 
tos humanos. ¿Y qué diremos de los términos propios de los oficios y artes industriales complicadísimas, como las fábricas de tejidos, de destilaciones, de tintes, de quincalla, \&c. \&c. (DRAE 1843: Prólogo).

De las afirmaciones del Prólogo se deduce, en definitiva, una actitud muy prudente de la Real Academia Española respecto al aumento del Diccionario en su novena edición, cuyas características mostraremos en los apartados siguientes.

\section{EL AUMENTO DEL DICCIONARIO: LA APORTACIÓN DE GREGORIO GARCÍA DEL POZO}

Como se ha señalado en $\S 2$, el aumento del Diccionario en la novena edición se realizó en dos fases. En primer lugar, se examinaron las voces aportadas por Gregorio García del Pozo, y se incluyeron y definieron las aprobadas en junta académica. Y, en segundo lugar, se introdujeron todos los cambios propuestos por los académicos encargados de revisar partes del Diccionario. Dado que las Actas reúnen información sobre la última voz de la lista de García del Pozo que se trataba en cada una de las juntas, es posible obtener algunos datos sobre el aumento que fue fruto de esta aportación. En la tabla siguiente (tabla 2) se reúne la información sobre todas las voces aportadas por García del Pozo según las Actas ${ }^{16}$, así como los datos sobre las ediciones del Diccionario académico que las incluyeron:

\begin{tabular}{|c|c|c|c|c|c|}
\hline DRAE 1843 & $\begin{array}{c}\text { DRAE } \\
1852\end{array}$ & DRAE 1869 & DRAE 1884 & $\begin{array}{c}\text { Otras } \\
\text { ediciones }\end{array}$ & $\begin{array}{c}\text { Voces no } \\
\text { incluidas } \\
\text { en el } \\
D R A E\end{array}$ \\
\hline $\begin{array}{l}\text { abonable, ad-libitum, asfixia, } \\
\text { barberil, céntuplo, conservatorio } \\
\text { (sust.), contraprincipio, } \\
\text { cosmopolita, despreocupación, } \\
\text { enjuiciamiento, esfumino, } \\
\text { geniazo, iniciativa, intachable, } \\
\text { jopo, malaquita (DRAE } 1817- \\
1832 ; \text { DRAE } 1843), \text { meloncillo, } \\
\text { nivelación, probatura, sanitario, } \\
\text { sentimental, trascurrir- } \\
\text { transcurrir, tenia, tulipán } \\
\text { (DRAE } 1739-1803 ; \text { DRAE } 1843) \text {, } \\
\text { véneto, visual (sust.), zelador } \\
\text { (Diccionario de autoridades } \\
\text { 1739-DRAE } 1791 ; \text { DRAE 1843) }\end{array}$ & $\begin{array}{l}\text { cotización, } \\
\text { deficiente, } \\
\text { paralizar }\end{array}$ & $\begin{array}{l}\text { monocordio, } \\
\text { personarse }\end{array}$ & $\begin{array}{l}\text { ailanto, } \\
\text { extralimitarse, } \\
\text { logia, } \\
\text { reorganización }\end{array}$ & $\begin{array}{l}\text { cuasidelito } \\
\text { (DRAE } \\
1925) \\
\text { afelpar } \\
\text { (DRAE } \\
1936)\end{array}$ & $\begin{array}{l}\text { beglierbes } \\
\text { punnar }\end{array}$ \\
\hline
\end{tabular}

Tabla 2. Voces aportadas por Gregorio García del Pozo al DRAE 1843.

A juzgar por los datos que ofrecen las Actas, la contribución de García del Pozo al DRAE 1843 fue significativa: de las cuarenta voces de que tenemos constancia, veintisiete fueron

16 A la lista de voces de García del Pozo que recoge Clavería (2016: 122-123) deben añadirse las palabras siguientes recogidas en las Actas: abonable, ad-libitum, afelpar, barberil, bergliebes, céntuplo, cuasidelito, esfumino, malaquita, punnar, tulipán, zelador. 
aceptadas para su incorporación a la novena edición, once se incluyeron en ediciones posteriores y solo dos no llegaron nunca a formar parte del lemario, la forma anticuada punnar y la voz que en las Actas parece leerse como beglierbes ${ }^{17}$, documentada en textos españoles como beglierbeyes ${ }^{18}$. Entre las voces propuestas por García del Pozo y aceptadas en la novena edición se encuentra léxico de carácter muy distinto; destacan las voces que en el diccionario académico (DRAE 1843), se calificarán de familiares, como barberil, geniazo, jopo o probatura:

BARBERIL. m. y s. fam. Lo que es propio de barberos.

GENIAZO. m. fam. Genio fuerte.

JOPO. inter. fam. Fuera de aquí.

PROBATURA. f. fam. Ensayo, prueba.

En el aumento debido a García del Pozo también se encuentran voces facultativas, como esfumino, "Pint. Rollito de piel suave para esfumar" (DRAE 1843), y palabras de uso extendido en el siglo XVIII, como, por ejemplo, los vocablos siguientes:

COSMOPOLITA. c. El que considera a todo el mundo como patria suya (DRAE 1843). (Voz incluida en Terreros 1767 [1786-1788] s. v. cosmopolita; $1 .^{\text {a }}$ doc. en el CORDE, José de Cadalso, 1773-1774)

SENTIMENTAL. adj. Lo que excita afectos tiernos, ó la persona propensa á ellos (DRAE 1843). (1. ${ }^{\text {a }}$ doc. en el CORDE, Leandro Fernández de Moratín, 1778-1822)

El examen de las listas de Gregorio García del Pozo también desvela el hecho de que contribuyó a incorporar a la novena edición voces que el diccionario académico había incluido en alguna de sus ediciones anteriores, pero que ya no se encontraban en la octava edición de 1837. Se trata, en concreto, de malaquita y de tulipán, y de la forma zelador. La voz malaquita se introdujo en el DRAE desde el Suplemento de 1817 y se mantuvo hasta el $D R A E$ 1832; en el DRAE 1837 aparecía la voz deformada con una errata, malaguita (entre las voces malandrín y malatía, donde le correspondía aparecer a malaquita), que se corrigió gracias a la aportación de García del Pozo. La reintroducción de las voces supuso también una revisión completa de las definiciones, tal y como puede comprobarse mediante la comparación de las entradas del Diccionario en sus distintas ediciones (tabla 3):

\begin{tabular}{|l|l|}
\hline $\begin{array}{l}\text { MALAGUITA. f. Piedra dura y opaca de un color } \\
\text { verde. [DRAE 1837] }\end{array}$ & $\begin{array}{l}\text { MALAQUITA. f. min. Piedra cobriza, verde, con } \\
\text { dibujos, por lo regular anules, y que se pulimenta como } \\
\text { el jaspe. [DRAE 1843] }\end{array}$ \\
\hline $\begin{array}{l}\text { TULIPAN. s. m. Flor conocida que tiene la figura de } \\
\text { un bonetillo, las hojas son de varios colores, y por lo } \\
\text { comun listadas de encarnado, no tiene olor particular. }\end{array}$ & $\begin{array}{l}\text { TULIPAN. m. Planta, cuya flor que tiene el mismo } \\
\text { nombre es muy estimada por la belleza de sus colores. } \\
\text { La flor consta de seis hojas, tres de ellas dentro y las } \\
\text { Esta flor vino de Turquía con el mismo nombre que en } \\
\text { aquel idioma significa bonete. [DRAE 1803] }\end{array}$ \\
$\begin{array}{l}\text { poco más largas que las segundas. Los hay de muchas } \\
\text { especies. [DRAE 1843] }\end{array}$ \\
\hline
\end{tabular}

17 Cf. Coronelli (1704), s. v. Beghilei-Beghi o Beyler-bey se explica que "preso i Turchi è titolo d'un Governatore d'una provincia dell'Impero Ottomano".

18 Cf. las Memorias históricas de los monarcas othomanos que escrivio en lengua toscana Iuan Sagredo [...], tradvzidas en castellanos por don Francisco de Olivares Mvrillo (1684: 329) o la Gazeta de Madrid, 19/01/1808, p. 64. 
ZELADOR. s. m. El que zela, cuidando del perfecto y exâcto cumplimiento de los ministerios, ú obligaciones, y observancia de las leyes. Zelator, zelotes. 2. El que por encargo, ú oficio tiene en las congregaciones, ó cofradías el cuidado particular de que no se falte á lo establecido, ó usado en ellas; y en los estudios de gramática se señala uno de los estudiantes de la clase, que llaman ZELADOR del aula. [DRAE 1791]

CELADOR, RA. s. m. y f. El que cela. Curator.

CELADOR. El que en las congregaciones y otros cuerpos, tiene por oficio, cuidar de que se cumpla lo dispuesto en sus estatutos. [...]

CELADOR. El que en el templo cuida de que se observe la modestia y silencio debido. [...]

CELADOR. El que en las escuelas cuida de que no se distraigan de sus estudios los discípulos. [...]

[DRAE 1803-1837]
ZELADOR. m. El que zela ó vigila: especialmente el destinado por la autoridad para ejercer vigilancia. [DRAE 1843]

CELADOR, RA. m. y f. El que cela. Curator. El que en las congregaciones y otros cuerpos tiene por oficio cuidar de que se cumpla lo dispuesto en sus estatutos. [...] El que en el templo cuida de que se observe la modestia y silencio debido. [...] El que en las escuelas cuida de que no se distraigan de sus estudios los discípulos.

[DRAE 1843]

Tabla 3. Comparación de entradas del DRAE en distintas ediciones.

En el caso de zelador la incorporación de esta forma en el DRAE 1843 introdujo una incongruencia, pues la palabra había pasado a regularizarse en celador desde el DRAE 1803, mientras que en el DRAE 1843 aparecen las dos formas celador y zelador, con sendas definiciones. En el DRAE 1869 se corrigió esta anomalía, de manera que zelador se incluyó ya solo como una forma con remisión a celador (tabla 4):

CELADOR, RA. m. y f. El que cela ó vigila, especialmente el destinado por la autoridad para ejercer vigilancia.

ZELADOR. m. CELADOR.

Tabla 4. Entradas del DRAE (1869).

No es posible analizar con más detalle la aportación de García del Pozo, puesto que, como se ha señalado, no disponemos del listado completo de las voces propuestas. No obstante, la muestra obtenida a través de la lectura atenta de las Actas y del análisis de los casos arriba expuestos da cuenta de la importancia de este trabajo, tanto por el número de voces que debió aportar, como por la revisión que supuso del Diccionario, al reintroducir lemas descartados en la edición anterior (tulipán), corregir erratas (malaquita por malaguita) y provocar la revisión de algunas definiciones.

Con el fin de conocer con más detalle las características del aumento de lemas en todo el $D R A E 1843$ se expondrá a continuación un acercamiento a los lemas y formas que se incluyen por primera vez en la novena edición, con especial atención a aquellos que introducen acepciones marcadas. 


\section{EL AUMENTO DEL DICCIONARIO: LEMAS Y FORMAS INCORPORADOS AL DRAE 1843}

A través de las posibilidades de búsqueda de la herramienta informática en línea Nuevo Tesoro Lexicográfico de la Lengua Española, NTLLE (Clavería/Freixas 2018b), ha sido posible reunir el listado completo de formas incorporadas al lemario del DRAE 1843. A partir de la búsqueda de cada una de las formas, se ha elaborado una base de datos con la información referente al lema en que aparece la forma, la marcación y el texto completo de la entrada lexicográfica. Esta compilación de datos permite conocer con exactitud el número de lemas (simples y compuestos) y el número de formas nuevas presentes en el DRAE 1843. Se reúne en la tabla siguiente (tabla 5) el total de lemas y de formas ${ }^{19}$ que constituyen el aumento de la novena edición:

\begin{tabular}{|c|c|c|c|c|c|}
\hline \multirow{2}{*}{ Letra } & \multicolumn{2}{|c|}{ Aumento } & \multirow{2}{*}{ Letra } & \multicolumn{2}{|c|}{ Aumento } \\
\hline & N. ${ }^{\circ}$ de lemas & N. ${ }^{\circ}$ de formas & & N. ${ }^{\circ}$ de lemas & N. ${ }^{\circ}$ de formas \\
\hline A & 59 & 61 & M & 26 & 29 \\
\hline B & 22 & 22 & $\mathrm{~N}$ & 9 & 9 \\
\hline $\mathrm{C}$ & 75 & 76 & $\tilde{N}$ & 0 & 0 \\
\hline $\mathrm{CH}$ & 3 & 4 & $\mathrm{O}$ & 7 & 7 \\
\hline $\mathrm{D}$ & 52 & 52 & $\mathrm{P}$ & 37 & 38 \\
\hline E & 36 & 37 & Q & 0 & 0 \\
\hline F & 16 & 16 & $\mathrm{R}$ & 31 & 32 \\
\hline G & 12 & 12 & $\mathrm{~S}$ & 23 & 24 \\
\hline $\mathrm{H}$ & 4 & 4 & $\mathrm{~T}$ & 27 & 27 \\
\hline I & 40 & 40 & $\mathrm{U}$ & 5 & 5 \\
\hline $\mathrm{J}$ & 8 & 9 & V & 16 & 16 \\
\hline $\mathrm{K}$ & 0 & 0 & $\mathrm{X}$ & 0 & 0 \\
\hline $\mathrm{L}$ & 18 & 18 & $\mathrm{Y}$ & 0 & 0 \\
\hline LL & 0 & 0 & Z & 4 & 4 \\
\hline
\end{tabular}

Tabla 5. Total de lemas y de formas que constituyen el aumento del DRAE (1843).

19 En el recuento de lemas se han tenido en cuenta como uno solo tanto los simples (ej. aberracion) como los compuestos (ej. montañica, ta). En el cómputo de las formas se han considerado todas las formas nuevas simples y derivadas que conforman los lemas (así, por ejemplo, montañica y montañita se cuentan como dos formas del lema compuesto montañica, ta) y las formas que se añaden a lemas ya presentes en el DRAE (como arbolcico y arbolcito, que se añaden al lema alborcillo ya en el DRAE 1837, para conformar el lema arbolcillo, cico, cito en el $D R A E$ 1843). No se han contado las formas debidas a la expresión de la moción de género, ya que esta se incluye de forma generalizada en los sustantivos. El listado completo de las formas que constituyen el aumento del $D R A E$ 1843 puede consultarse en la página web del Grupo de Investigación "Historia interna del Diccionario de la lengua castellana de la Real Academia Española en el siglo XIX (1817-1852)", < $\underline{\text { https://draesxix.wixsite.com/draesxix/ }}$ lemateca $>$. 
En total, se trata de un aumento de 530 lemas $^{20}$ y 542 formas nuevas ${ }^{21}$, que se sitúa muy por encima del que se produjo en la octava edición, con 267 lemas y 280 formas nuevas, y algo inferior al que se realizó en la décima, con 656 lemas y 726 formas nuevas. El aumento se reparte entre todas las letras, aunque en la primera mitad del Diccionario es más abundante, de manera que la $A$ (59 lemas nuevos), la $C$ (75), la $D(52)$, la $I$ (40) y la $E(36)$ concentran el mayor número de incorporaciones.

Parte del aumento está constituido por voces derivadas, como el léxico representado por 27 formas con sufijación aumentativa, diminutiva ${ }^{22}$ y despreciativa ${ }^{23}$. Por lo general, los diminutivos incorporados en el DRAE 1843 se suprimieron en el $D R A E 1884^{24}$, cuando se optó por eliminar del Diccionario académico este tipo de léxico. En cambio, en la última edición del $D R A E 2014$ se mantienen muchas de las voces derivadas de sufijos aumentativos o despreciativos que se introdujeron por primera vez en el $D R A E 1843^{25}$, en su mayoría ya lexicalizadas con acepciones no apreciativas: calabazazo, caseron, casuca, casucha, cintajo, colleron, dulzarron, ladronzuelo, larguirucho, palabrota, papirotazo, papelote, papelucho y señoron. Aumentó también el número de otros derivados fácilmente formables, como las voces en -mente, con diez voces que en su mayoría se mantienen hasta el DRAE $2014^{26}$, o los superlativos en -ísimo, con tres lemas, de los que solo sumarisimo se encuentra en el DRAE 2014.

En el aumento destaca la frecuencia con que en el DRAE 1843 se incorporaron voces derivadas de una misma raíz, lo que muestra una tendencia a tratar de introducir en el lemario todas las palabras documentadas de una misma familia. Se encuentran numerosos ejemplos de este procedimiento: celera, celillo, celosamente, celosisimo; contertuliano, contertulio; confinacion, confinamiento; decrecer, decreciente; documentalmente, documentar; desbarahuste, desbarahustar; desbarajuste, desbarajustar; francmason, francmasonería; ideológico, ideólogo; impopular, impopularidad; inmoral, inmoralidad; insubordinar, insubordinado; masonería, masónico; pindonga, pindonguear; recolectar, recolector; regicida, regicidio, tradicional, tradicionalmente; vals, valsar; vertebrado, vertebral.

20 En siete casos se trata de lemas que se reintroducen en 1843 en el $D R A E$ después de haber sido eliminados en alguna edición anterior. Así ocurre con desaseado (Diccionario de autoridades 1732-DRAE 1822, DRAE 1843, DRAE 1884-2014), florescer (DRAE 1803-1817, DRAE 1843-2001), parentacion (Diccionario de autoridades 1737-DRAE 1803, DRAE 1843-2014), teyo (DRAE 1803-1832, DRAE 1843-2001), tresañal (DRAE 1803-1817, DRAE 1843-2001), ultra (Diccionario de autoridades 1739-DRAE 1803, DRAE 1843-2014) y volado (Diccionario de autoridades 1739-DRAE 1822, DRAE 1843, DRAE 1884-2014).

21 No se han contado ni como lemas ni como formas nuevas las erratas encanamiento del DRAE 1843 por encanamento (que aparece en el Diccionario de autoridades-DRAE 1837 y se reincorpora al lemario en el DRAE 1884) ni manuela del DRAE 1843 por mañuela (desde el Diccionario de autoridades-DRAE 1837 y a partir del DRAE 1852).

22 Desde el Diccionario de autoridades se incluían ya diminutivos en el diccionario académico (Ruhstaller 2001). 23 Se trata de arbolcico, arbolcito, calabazazo, caseron, casuca, celillo, cintajo, comedion, colleron, duquesita, escritorcillo, escritorcito, jicaron, ladronazo, ladronzuelo, larguirucho, lejillos, modito, montañica, montañita, palabrota, papirotazo, papelote, papelucho, pillastron y señoron.

24 Excepto duquesita, que se mantiene hasta el DRAE 1843. Algunos diminutivos, arbolcico, arbolcito, escritorcillo, se documentan solo en el DRAE 1843. Otros se documentan hasta el DRAE 1869: celillo, escritorcito, lejillos, modito, montañica y montañita.

25 De este tipo de voces únicamente ladronazo se incorpora en el DRAE 1843 y tiene su última aparición en el DRAE 1869 .

26 Se incorporaron al DRAE 1843 y se mantienen hasta el DRAE 2014 celosamente, estrepitosamente, eventualmente, indefinidamente, inexorablemente, inversamente, oficialmente y tradicionalmente; mientras que las voces ávidamente y documentalmente, incluidas por primera vez en el DRAE 1843 se registraron hasta el DRAE 1984. 
De las voces incorporadas por primera vez en el DRAE 1843, 96 entradas lexicográficas contienen abreviaturas que en alguna de sus acepciones cumplen la misma función que las marcas empleadas en la lexicografía actual ${ }^{27}$ : informar sobre el ámbito de uso desde el punto de vista diacrónico, diafásico, estilístico, diatópico o diatécnico. En total, se han registrado 97 acepciones marcadas con las abreviaturas que se reúnen en el cuadro siguiente (tabla 6):

\begin{tabular}{|c|c|c|}
\hline $\begin{array}{l}\text { Marcas } \\
\text { diacrónicas }\end{array}$ & $\begin{array}{l}\text { N. }{ }^{\circ} \\
\text { acepciones }\end{array}$ & Lemas \\
\hline ant. & 9 & $\begin{array}{l}\text { alcayoba, caramida, celera, eruga, micer, mosen, novallo, nudrimento, } \\
\text { torgado }\end{array}$ \\
\hline fam. & 24 & $\begin{array}{l}\text { adelanto, anticipo, bailoteo, barberil, campechano, chiquillería, chirúmen } \\
\text { o churúmen, comadrear, contertulio, enredijo, geniazo, guapote, jopo, } \\
\text { larguirucho, miedoso, mostense, potingue, probatura, reñidura, reparto, } \\
\text { secretear, tole, tollina, triquiñuela }\end{array}$ \\
\hline met. / Metaf. & 6 & aberracion, escision, involucrar, neutralizar, orientar, parapetarse \\
\hline Poet. & 3 & circunfuso, turgido, undivago \\
\hline Prov. / prov. & 2 & agobio, cirolero \\
\hline $\begin{array}{l}\text { prov. Ar. / prov. } \\
\text { Arag. }\end{array}$ & 4 & alud, buro, cantal, desgay \\
\hline prov. de And. & 2 & achatar, cancela \\
\hline Prov. de Gal. & 1 & berso \\
\hline anat. / Anat. & 2 & lumbar, vertebrado \\
\hline Arq. & 1 & entramar \\
\hline Astr. & 3 & aberracion, culminante, deviacion \\
\hline Blas. & 1 & tortillos \\
\hline Bot. & 1 & líquen \\
\hline Carp. & 1 & borriquete \\
\hline Esc. & 1 & torso \\
\hline for. & 9 & $\begin{array}{l}\text { condómino, espontanearse, excarceracion, incautarse, indagatorio, } \\
\text { infringir, interdicto, premoriente, refeccionario }\end{array}$ \\
\hline Fort. & 2 & aspillera, parapetarse \\
\hline Geog. & 1 & orientar \\
\hline Geom. & 1 & exaedro \\
\hline Gram. & 1 & elision \\
\hline Hist. nat. & 2 & mandril, portaalmizcle \\
\hline Impr. & 1 & entredos \\
\hline leg. & 1 & iniciativa \\
\hline Med. / med. & 7 & amáurosis, asfixia, deletéreo, deviacion, gástrico, mucosidad, protuberancia \\
\hline Milic. / Mil. & 5 & carronada, desfile, dispersar, escalafon, pontonero \\
\hline
\end{tabular}

27 Detalladas reflexiones sobre los usos que se han otorgado a las marcas en la lexicografía española se encuentran en las propuestas de marcación para un diccionario histórico recogidas en Gómez/Carriazo (2010). 


\begin{tabular}{|l|l|l|}
\hline $\begin{array}{l}\text { Marcas } \\
\text { diacrónicas }\end{array}$ & $\begin{array}{l}\mathbf{N}^{\mathbf{o}} \\
\text { acepciones }\end{array}$ & Lemas \\
\hline Náut. & 3 & escuna, orientar, troceo \\
\hline Pint. / Pint. & 2 & amaneramiento, esfumino \\
\hline Ret. & 1 & etopeya \\
\hline
\end{tabular}

Tabla 6. Acepciones marcadas del aumento del DRAE (1843).

Si bien, como se mostrará más adelante, no todas las voces con usos restringidos presentan marcas, el análisis de las acepciones marcadas permite una primera aproximación a la caracterización de una parte significativa del aumento en el DRAE 1843. Como puede observarse, la mayoría de marcas se refieren a usos relacionados con las artes y las ciencias, con 49 acepciones marcadas. En segundo lugar, destaca el conjunto de acepciones con marcas referidas a restricciones estilísticas, con un total de 33 acepciones. Más reducido en esta edición es el número de nuevas acepciones marcadas con una indicación de carácter diacrónico, un total de 12, o diatópico, únicamente 9.

Tal y como ocurre en ediciones anteriores, se observa un aumento de acepciones marcadas en áreas de especialidad que desde el Diccionario de autoridades han estado abundantemente representadas, como el ámbito de lo forense o lo legal, con 10 acepciones nuevas; el área de lo militar y la fortificación, con 5 y 2 acepciones, respectivamente; o la náutica, con 3 acepciones. En menor medida, se incluyeron también acepciones referidas a ciencias que a lo largo del siglo XIX protagonizaron notables avances en el conocimiento, como la medicina, con 7 acepciones nuevas en el DRAE 1843 con la marca "med.", y 2 bajo la marca "anat.", o la historia natural ${ }^{28}$, con 3 acepciones marcadas con la abreviatura "hist. nat.", y una con "bot.".

Debe tenerse en cuenta que, como es habitual en los diccionarios académicos, no todas las acepciones relacionadas con un área de especialidad reciben una marca. Incluso en áreas muy representadas en el DRAE, como la náutica (bireme, lugre), la historia natural (belladona, cedoaria, colibrí, luisa, tenia) o la medicina (antiflogístico) se incorpora léxico no marcado. Véanse, por ejemplo, los casos siguientes:

BIREME. f. Nave antigua de dos órdenes de remos.

LUGRE. m. Embarcacion pequeña de tres palos.

BELLADONA. f. Planta narcótica de que se hace uso en la medicina.

CEDOARIA. f. Raiz medicinal redonda, nudosa, de sabor acre algo amargo, y de olor aromático, que proviene de una yerba de la India oriental, que echa las hojas de ligura de hierro de lanza, sostenida de sus pezones.

COLIBRÍ. m. Avecilla muy pequeña, semejante al pájaro mosca, y de la cual hay varias especies.

LUISA. f. Planta medicinal, cuyas hojas son largas, estrechas y de un verde claro: su olor es semejante al del toronjil.

TENIA. f. Nombre dado á un género de lombrices del cual hay varias especies. Tienen el cuerpo muy aplanado, por lo comun son muy largas, y rara vez hay mas de una en las entrañas.

ANTIFLOGÍSTICO. adj. Lo que calma la inflamacion; refrigerante, debilitante.

28 Véase en Gómez de Enterría (2018) el reflejo de las voces de ciencias naturales en el DRAE 1817. 
DIAGNÓSTICO ${ }^{29}$. El conjunto de signos que sirven para fijar el caracter peculiar de una enfermedad.

Entre el léxico no marcado perteneciente a áreas de especialidad, destaca en el DRAE 1843 el aumento de voces que pueden relacionarse con dos ámbitos: la retórica y la política. Entran por primera vez en el diccionario académico aticismo, etopeya, fraseología, galimatías, grandilocuencia, lucidez, monserga, perorata, personificar y preopinante, con acepciones referidas a la oratoria:

ATICISMO. m. Cierta gracia y delicadeza, que distingue á los escritores dramáticos de la escuela de Atenas.

ETOPEYA. Ret. Descripcion de los usos y costumbres de alguno.

FRASEOLOGÍA. El modo de ordenar las frases, peculiar á cada escritor.

GALIMATÍAS. m. Lenguaje oscuro por la impropiedad de la frase ó por la confusion de las ideas. Es voz recientemente admitida.

GRANDILOCUENCIA. s. Calidad que constituye elevado y sublime el estilo.

LUCIDEZ. f. Claridad. Se aplica á los escritos ó discursos.

MONSERGA. f. Lenguaje confuso y embrollado.

PERORATA. f. Razonamiento ú oracion molesta ó inoportuna

PERSONIFICAR. a. Dar vida y atributos de seres racionales á los que no lo son y aun á los afectos del ánimo. / r. Aludir á personas determinadas en los discursos ó escritos.

PREOPINANTE. adj. Da este nombre el que está perorando en alguna junta ú otra corporacion á cualquiera de los individuos que le han precedido en el uso de la palabra.

Únicamente etopeya recibe la marca Ret., probablemente porque se trata de una palabra bien definida en los manuales clásicos de retórica, mientras que otras no pertenecen al ámbito de la tratadística, sino al uso generalizado, como galimatías, de la que se reconoce que "es voz recientemente admitida". Probablemente el hecho de carecer de tratados que avalen un uso especializado es la causa de que el $D R A E 1843$ no incluya la marca Ret. en la mayoría de las voces referidas a la oratoria. El mismo motivo, la falta de obras de especialidad de referencia, puede explicar que esta edición carezca de una marca para las voces de la política ${ }^{30}$, un ámbito con un aumento de voces considerable en la novena edición del Diccionario académico:

ABSOLUTISMO. m. Sistema del gobierno absoluto.

ABSOLUTISTA. adj. Partidario del gobierno absoluto.

ANARQUISTA. El que desea o promueve la anarquía.

FEDERAL. adj. Federativo.

REVOLUCIONARIO, RIA. adj. Lo que pertenece á la revolucion. / Alborotador, turbulento.

Dada la ausencia de autoridades en el Diccionario académico, resulta difícil conocer las fuentes de procedencia de las voces y acepciones que constituyen el aumento, pero debe suponerse, según lo arriba expuesto en las Reglas de 1838, que la documentación en tratados de especialidad debió de ser una de las procedencias fundamentales, y es posible que condicionara también la marcación.

29 En el Diccionario de Núñez de Taboada (1825) esta voz se acompañaba de la marca Med.

30 El diccionario de Domínguez (1846-1847) incluirá la abreviatura "Polít." para acotar el uso de voces como federalismo. 
A partir de 1838 comenzó a trabajarse en la elaboración de una "nueva lista de los autores, de los cuales se hayan de escoger las autoridades para comprobar los artículos del Diccionario" (RAE 1838: 23). Una versión de dicha lista se publicó en 1870 y en ella se hallan numerosos tratados de especialidad que pudieron haberse ido empleando como fuentes de las obras lexicográficas del Diccionario académico. Un ejemplo del tipo de tratados modernos que se añaden al listado lo constituye, entre las fuentes del ámbito militar, el Prontuario de artillería para el servicio de campaña, por orden alfabético o de materias, obra de Ramón de Salas publicada por primera vez en 1828 y en una segunda edición en 1833. Entre las voces tratadas por extenso en este manual se encuentran las carronadas, voz que en singular se incluye por primera vez en el DRAE 1843 (tabla 7):

\begin{tabular}{|l|l|}
\hline \multicolumn{1}{|c|}{ Salas $\left(\mathbf{1 8 3 3}^{2}\right)$} & \multicolumn{1}{c|}{ DRAE 1843 } \\
\hline CARRONADAS & $\begin{array}{l}\text { CARRONADA. f. Milic. Cañon corto, de } \\
\text { grueso calibre, montado sobre correderas. }\end{array}$ \\
$\begin{array}{l}\text { No son otra cosa que un cañon de hierro, corto, para } \\
\text { calibres mayores hasta 48 y } 60 \text { libras de bala. En } \\
\text { lugar de cascabel suelen tener un asa. }\end{array}$ & \\
$\begin{array}{l}\text { Su uso principal es para la marina, y se sirven sobre } \\
\text { cureñas de esta clase. }\end{array}$ & \\
\hline
\end{tabular}

Tabla 7. Información sobre carronada en Salas $\left(1833^{2}\right)$ y en el DRAE 1843.

Si bien la definición no se traslada de forma literal en el $D R A E 1843$, por lo que no puede asegurarse que Salas $\left(1833^{2}\right)$ sea la fuente directa, ambos textos presentan el mismo tipo de información sobre la carronada en el mismo orden, aportando una equivalencia del arma con un "cañón corto", datos sobre el calibre y sobre el lugar en el que se asienta. Es probable que, además de las autoridades, se emplearan otras fuentes de documentación para las voces de especialidad y, en general, para todo el aumento del Diccionario. De las 102 acepciones nuevas en el DRAE 1843, 48 aparecen en el Diccionario de la lengua castellana de Manuel Núñez de Taboada (1825), fuente que, como ha demostrado Clavería (2007), fue fundamental en el aumento del DRAE 1817 y del DRAE $1832^{31}$.

En relación con el léxico con acepciones introducidas por marcas de carácter diafásico, destaca la abundancia de voces familiares ${ }^{32}$, lo que constata el interés de la Academia, manifestado en otras ediciones (véase Azorín 2018, para el $D R A E$ 1817), por reunir información sobre el habla cotidiana. Las voces familiares incorporadas en el DRAE 1843 son una muestra de la creatividad léxica en esta variedad de la lengua, ya que se añaden numerosas voces derivadas en -il (barberil), -ear (comadrear, secretear), -oso (miedoso), -ura (probatura, reñidura); en los aumentativos -azo (geniazo) y -ote (guapote); o en los despectivos -ucho (larguirucho) y -uela (triquiñuela).

En cambio, es muy reducida la aportación de voces con una marca estilística del ámbito de la poética, con acepciones empleadas en el lenguaje literario, de las que solo se recogen

31 En posteriores estudios sobre la definición, analizaré con más detalle la posible influencia del diccionario de Núñez de Taboada (1825) en el DRAE 1843.

32 Desde el DRAE 1817 la única marca para las voces familiares es la abreviatura “fam.” (Azorín 2018). 
circunfuso, turgido y undivago. Las tres voces literarias incluidas en el DRAE 1843 son latinismos de muy poco uso. Circunfuso, "lo que es está esparcido por todas partes" (DRAE 1843 ) parece ser voz recurrente solo en las obras de Lope de Vega, únicas documentaciones para esta voz en el CORDE y en el Fichero general de la RAE; turgido, "turgente" (DRAE 1843 ) únicamente se encuentra en el CORDE en el sintagma "perlas turgidas", referido a los pechos de una dama en una Selva de epíctetos anónima (c. 1500); y undívago, "lo que ondea con libertad á manera de las olas" (DRAE 1843) es la única voz de uso más recurrente en la lengua literaria, con documentaciones en el CORDE en las poesías del Conde de Villamediana (1599-1622) y en el teatro de Leandro Fernández de Moratín (1778-1822), y en el Fichero general de la RAE, en Lope de Vega.

En cuanto al léxico con marcas diacrónicas, se mantiene la tendencia del Diccionario académico a aumentar el léxico anticuado, con la incorporación de nuevas voces marcadas con "ant.", abreviatura que desde el DRAE 1817 —en la que se eliminaron las marcas para raro y poco usado (Jiménez Ríos 2018: 401 y ss.) - se empleó para las voces sin uso. Como en ediciones anteriores, el aumento de voces anticuadas, que responde al objetivo de que el Diccionario permita un acercamiento histórico al léxico del español, va acompañado también de la supresión de lemas, que supone una actualización de los contenidos del repertorio lexicográfico académico (Jiménez Ríos 2018: 406-407). En este caso, y a diferencia de otras ediciones, la supresión de voces anticuadas, veinticinco en total, fue mayor que el aumento, de doce lemas.

A diferencia del léxico anticuado, los neologismos no van acompañados de ninguna marca, aunque en ocasiones contienen en la definición indicaciones referidas a su uso moderno. Ocurre, por ejemplo, en clasicismo, galimatías, esplin y manufacturero:

CLASICISMO. m. El sistema ó cuerpo de doctrinas de la literatura greco-romana. Es voz nuevamente introducida.

GALIMATÍAS. m. Lenguaje oscuro por la impropiedad de la frase ó por la confusion de las ideas. Es voz recientemente admitida.

MANUFACTURERO, RA. adj. Lo que pertenece á la manufactura, como la clase MANUFACTURERA. ES VOZ de uso reciente.

Finalmente, por lo que se refiere al léxico con marcación diatópica, presente en el Diccionario académico desde el Diccionario de autoridades (Salvador Rosa 1985), forma también parte del aumento, aunque se reduce únicamente a nueve voces, contribución en este caso no muy significativa, pues a su vez en el DRAE 1843 se suprimió una voz provincial (borras), una provincial de Murcia (armajara), tres provinciales de Aragón (alatonero, rugiar y saboca) y una de las Indias (esgarro).

\section{CONCLUSIONES}

En la presente contribución se ha realizado un primer acercamiento a los procedimientos empleados para el aumento de voces en el DRAE 1843. A través del análisis de la información procedente de los resúmenes de las sesiones académicas en las Actas de la Corporación se han mostrado los detalles del trabajo corporativo y se han descrito cuestiones fundamentales sobre la novena edición del Diccionario académico. En primer lugar, se ha demostrado la relación existente entre los dos proyectos lexicográficos de la Real Academia Española, el Diccionario de autoridades y el Diccionario usual, que consiste no solo en el trasvase de 
contenidos de una a otra obra, sino también en el hecho de que ambas se rigen por unos mismos principios metodológicos expuestos en 1838 en las Nuevas reglas para la corrección y aumento del Diccionario. En segundo lugar, se ha constatado la pervivencia de métodos de trabajo colaborativo que, para el $D R A E$ 1843, tuvieron lugar en dos fases: una primera de análisis y aprovechamiento de materiales aportados por Gregorio García del Pozo y una segunda de revisión y aumento del Diccionario a través de un trabajo de actualización de los contenidos publicados en los cuadernos del DRAE 1837 repartidos entre los académicos.

En cuanto al aumento, mediante el estudio de las afirmaciones contenidas en las Reglas de 1838 y en el Prólogo al DRAE 1843, ha sido posible constatar el mantenimiento en esta edición de criterios restrictivos respecto a la aceptación de neologismos y de voces relacionadas con los ámbitos de las artes, ciencias y oficios. La definición de los objetivos del DRAE 1843 en el Prólogo confirma la voluntad de los académicos de defender la propuesta de un Diccionario usual y normativo dirigido a recoger las voces de uso común, alejándose de planteamientos de carácter enciclopédico. Esta justificación se explica, principalmente, por el contexto histórico en el que se publica el DRAE 1843, tras la edición del Panléxico de Peñalver (1842), un diccionario llamado universal que desde su planteamiento se había presentado como una crítica y superación del trabajo realizado por la Real Academia Española.

Finalmente, el análisis de los lemas y formas que se incorporan por primera vez en el $D R A E$ 1843, especialmente de aquellos que incluyen acepciones con marcas diatécnicas, diafásicas, diacrónicas y diatópicas, muestra que en esta edición se produjo un aumento moderado, 530 voces y 542 formas nuevas, por debajo de las cifras de la edición siguiente, de 1852. En el aumento se continúa con la tendencia de ediciones anteriores del DRAE a incrementar el lemario a través de formas derivadas fácilmente formables y de derivados de una misma raíz léxica. Por lo que se refiere a las voces marcadas, se constata un uso más frecuente de las marcas para acepciones referidas a voces de las artes, ciencias y oficios, y para acepciones de usos familiares. En el léxico de especialidad se observa un uso desigual de las marcas, incluso en voces de la misma área, como ha podido comprobarse en las acepciones de la náutica, de la historia natural o de la jurisprudencia, que pueden incluirse en el Diccionario con o sin marca restrictiva. Asimismo, se observa cómo las marcas se reservan para ámbitos tradicionalmente muy representados en el $D R A E$, mientras que otras áreas muy presentes en el aumento de la novena edición, como las voces de la política o de la retórica, no reciben marcas. Como se apunta en el presente trabajo, en estudios posteriores sobre la marcación en los diccionarios decimonónicos académicos, debería tenerse en cuenta la posible relación existente entre la presencia de marcas y las posibles fuentes de especialidad consultadas. En cuanto al léxico con marcas diacrónicas, se constata la tensión existente entre la voluntad de seguir aumentando el Diccionario con léxico desusado, aportando así un valor histórico a la obra lexicográfica, y entre el objetivo de actualizar el lemario mediante la supresión de voces arcaicas. Por último, el reducido número de voces dialectales marcadas en el aumento al $D R A E 1843$ es señal de que esta no fue una de las áreas privilegiadas en esta edición. 


\section{REFERENCIAS BIBLIOGRÁFICAS}

Actas = Real Academia Española (1791-1900): Libro de acuerdos de la Real Academia Española, desde el 29 de junio de 1837 hasta el 16 de noviembre de $1843^{33}$.

Alvar Ezquerra, M. (1983): "Los prólogos del Diccionario académico. Nomenclatura específica y microestructura”, Revista de Filología Española, LXIII, pp. 205-222.

Alvar Ezquerra, M. (1992): "Los diccionarios académicos y el problema de los neologismos". En C. G. Reigosa (coord.). El neologismo necesario. Madrid: Fundación EFE, pp. 51-70.

Álvarez de Miranda, P. (2001): "La lexicografía académica de los siglos XVIII y XIX”. En I. Ahumada (coord.). Cinco siglos de lexicografía del español. Jaén: Universidad de Jaén, pp. 35-61.

Azorín, D. (1994-1995): "El Nuevo Diccionario de la Lengua Castellana de Vicente Salvá", Estudios de Lingüística de la Universidad de Alicante, 10, pp. 9-20.

Azorín, D. (2000): Los diccionarios del español en su perspectiva histórica. Alicante: Publicaciones de la Universidad de Alicante.

Azorín, D. (2002): "Salvá y la Academia Española: dos posturas frente a la recepción de tecnicismos en el diccionario de la lengua". En Esparza, M. A. et alii (eds.). Estudios de historiografia lingüística. Actas del III Congreso Internacional de la Sociedad Española de Historiografía Lingüistica. Hamburg: Helmut Buske, pp. 777-788.

Azorín, D. (2018): "El léxico con marcación estilística". En Clavería/Freixas (2018a), pp. 427-458.

Carriet, E. (en prensa): "La séptima edición del diccionario académico (DRAE 1832)", Revista de Lexicografia, 24.

Clavería, G. (2003): "La Real Academia Española a finales del siglo XIX: el Diccionario de la lengua castellana de 1899 (13. a edición)", Boletín de la Real Academia Española, LXXXIII, pp. 255-336.

Clavería, G. (2007): "Historia del léxico en los diccionarios: la deuda del Diccionario de la lengua castellana de la Real Academia Española con los diccionarios de M. Núñez de Taboada", Revista de Historia de la Lengua Española, 2, pp. 3-27.

Clavería, G. (2016): De vacunar a dictaminar: la lexicografía académica decimonónica y el neologismo. Madrid/Frankfurt: Iberoamericana/Vervuert.

Clavería, G. y M. Freixas (coords.) (2018a): El diccionario de la Academia en el siglo XIX: la quinta edición (1817) al microscopio. Madrid: Arco/Libros.

Clavería, G. y M. Freixas (2018b): "El NTLLE: un museo lexicográfico como base de datos lingüísticos y lexicográficos", Cuadernos del Instituto Historia de la Lengua, 11, pp. 117-138.

CORDE: Real Academia Española: Corpus diacrónico del español. Banco de datos, <http://www. rae.es>.

Coronelli, Fra V. (1704): Biblioteca Universale Sacro-Profana, antico-moderna, in cui si spiega con ordine Allfabetico ogni voce, anche straniera, che può aver significato nel nostro Idioma Italiano, Appartenente A Qualunque Materia. Tomo V. Venecia: Antonio Tivani.

Cortázar, Daniel (1899): "Discurso del Exmo. Sr. D. Daniel de Cortázar". En Discursos leídos ante la Real Academia Española en la recepción públoca del Excmo. Sr. D. Daniel de Cortázar el día 23 de abril de 1899. Madrid: Est. Tip. de la viuda é hijos de Tello.

CREA: Real Academia Española: Corpus de referencia del español actual. Banco de datos, $<\mathrm{http}: / /$ www.rae.es>.

Diccionario de autoridades $=$ Real Academia Española (1726-1739): Diccionario de la lengua castellana, en que se explica el verdadero sentido de las voces, su naturaleza y calidad con las phrases o modos de hablar, los proverbios o refranes, y otras cosas convenientes al uso de la lengua. 6 vols. Madrid: Imprenta Francisco del Hierro.

33 Agradezco la consulta de los materiales del archivo a la Real Academia Española y, en especial, a Covadonga de Quintana. 
Diccionario de autoridades (1770) = Real Academia Española (1770): Diccionario de la lengua castellana, segunda impresión corregida y aumentada. Tomo primero: A-B. Madrid: Joachin Ibarra.

Domínguez, Ramón Joaquín (1846-1847 [1853]): Diccionario Nacional o Gran Diccionario Clásico de la Lengua Española. 5. a ed. Madrid/París: Establecimiento de Mellado [consultado a partir del NTLLE].

DRAE 1817 = Real Academia Española (1817): Diccionario de la lengua castellana, quinta edición. Madrid: Imprenta Real.

DRAE 1832 = Real Academia Española (1832): Diccionario de la lengua castellana, séptima edición. Madrid: Imprenta Real.

DRAE 1837 = Real Academia Española (1837): Diccionario de la lengua castellana, octava edición. Madrid: Imprenta Nacional.

DRAE 1843 = Real Academia Española (1843): Diccionario de la lengua castellana, novena edición. Madrid: Imprenta de D. Francisco María Fernández.

DRAE 1852 = Real Academia Española (1852): Diccionario de la lengua castellana, décima edición. Madrid: Imprenta Nacional.

DRAE 1869 = Real Academia Española (1869): Diccionario de la lengua castellana, undécima edición. Madrid: Imprenta de Don Manuel Rivadeneyra.

DRAE 1884 = Real Academia Española (1884): Diccionario de la lengua castellana, duodécima edición. Madrid: Imprenta de D. Gregorio Hernando.

DRAE 1899 = Real Academia Española (1899): Diccionario de la lengua castellana, décimatercia edición. Madrid: Imprenta de los Sres. Hernando y compañía.

DRAE 1984 = Real Academia Española (1984): Diccionario de la lengua española, vigésima edición. Madrid: Calpe.

DRAE 2014 = Real Academia Española y Asociación de Academias de la Lengua Española (2014): Diccionario de la lengua española, vigesimotercera edición. Madrid: Espasa.

Fichero general $=$ Real Academia Española: Fichero general de la lengua española. $<\mathrm{http} / / /$ web.frl. es/fichero.html $>$.

Freixas Alás, M. (2006): "La técnica lexicográfica en el Diccionario de autoridades: la contribución del académico Juan Ferreras”. En Campos, M. y J. I. Pérez Pascual (coords.). El diccionario de la Real Academia Española: ayer y hoy. Anexos de la Revista de Lexicografia,1. A Coruña: Universidade da Coruña, pp. 83-97.

Freixas Alás, M. (2010): Planta y método del Diccionario de autoridades. Orígenes del método lexicográfico de la Real Academia Española (1713-1739). Anexos de la Revista de Lexicografia, 14. A Coruña: Universidade da Coruña.

García del Pozo, Gregorio (1854): Suplemento de la fe de erratas de la 10. ${ }^{\circ}$ edición del Diccionario de la Real Academia Española y su Prontuario de ortografía o sea continuación del Suplemento de la fe de erratas de la 9. ${ }^{a}$ edición y algunas notas a sus ediciones de ortografía. Madrid: Imprenta de la Viuda de Burgos.

Gómez de Enterría, J. (2018): "Las voces de las ciencias naturales y áreas afines". En Clavería/Freixas (2018a), pp. 275-311.

Gómez Martínez, M. y J.R. Carriazo (2010): La marcación en lexicografia histórica. San Millán de la Cogolla: Cilengua.

Jiménez Ríos, E. (2013): La crítica lexicográfica y el Diccionario de la Real Academia Española. Obras y autores contra el Diccionario. Anexos de la Revista de Lexicografía, 21. A Coruña: Universidade da Coruña.

Jiménez Ríos, E. (2018): "El léxico con marcación diacrónica". En Clavería/Freixas (2018a), pp. 399-426.

Lemateca: Base de datos del Grupo de Investigación "Historia interna del Diccionario de la lengua castellana de la Real Academia Española en el siglo XIX (1817-1852)", <https://draesxix.wixsite. com/draesxix/lemateca>. 
Núñez de Taboada, M. (1825): Diccionario de la lengua castellana para cuya composición se han consultado los mejores vocabularios de esta lengua, y el de la Real Academia Española últimamente publicado en 1822; aumentado con más de 5000 voces o ortículos que no se hallan en ninguno de ellos. Paris: Seguin [consultado a partir del NTLLE].

Peñalver, J. (1842): Panléxico. Diccionario universal de la lengua castellana. Madrid: Imprenta de D. Ignacio Boix.

Prontuario de ortografía de la lengua española (1854): Real Academia Española: Prontuario de ortografía de la lengua española, quinta edición. Madrid: Imprenta Nacional.

Reglas (1764): Reglas que ha formado la Academia Española para la corrección y aunemto del Diccionario de la Lengua Castellana. Madrid: Antonio Pérez de Soto.

Reglas (1743) = Real Academia Española: Reglas, que formó la Academia en el año de 1743 y mandó observassen los señores Académicos, para trabajar con uniformidad en la corrección, y Suplemento del Diccionario. [s. 1.]: [sin pie de imprenta].

Reglas $(1757)=$ Real Academia Española: Nuevas reglas que ha formado la Academia Española para la correccion y aumento del Diccionario. Año 1757. Manuscrito 415 de la Biblioteca de la Real Academia Española.

Reglas $(1760 / 1770)=$ Real Academia Española: Reglas para la corrección y aumento del diccionario. Madrid: [sin pie de imprenta].

Reglas $(1764)=$ Real Academia Española: Reglas que ha formado la Academia Española para la correccion y aumento del Diccionario de la Lengua Castellana. Madrid: Imprenta de Antonio Pérez de Soto.

Reglas (1838): Real Academia Española: Reglas para la corrección y aumento del diccionario. Madrid: Imprenta Nacional.

Rodríguez, F. y C. Garriga (2010): "La teoría lexicográfica de la Academia en los siglos XVIII y XIX a través de las reglas". Quaderns de Filología. Estudis Lingüístics, 15, pp. 31-56.

Ruhstaller, S. (2001): "Descripción gramatical y tratamiento lexicográfico de los diminutivos en el Diccionario de autoridades". En A. M. " Medina Guerra (coord.), Estudios de lexicografía diacrónica del español (V Centenario del "Vocabularium Ecclesiasticum de Rodrigo Fernández de Santaella. Málaga: Universidad de Málaga, pp. 181-209.

Salas, R. de (1833): Prontuario de artillería para el servicio de campaña, por orden alfabético o de materias, segunda edición. Madrid: Oficina de E. Aguado.

Salvá, V. (1846): Nuevo diccionario de la lengua castellana, que comprende la última edición íntegra, muy rectificada y mejorada del publicado por la Academia Española [...]. París: Vicente Salvá [consultado a partir del NTLLE].

Salvador Rosa, A. (1985): "Las localizaciones geográficas en el Diccionario de autoridades". Lingüistica Española Actual, 7, pp. 103-139.

San Vicente, F. (2010): “Autor, norma y uso en los prólogos del DRAE (1780-2001)”. En Chierichetti, L. y G. Garofalo (eds.). Lengua y Derecho: líneas de investigación interdisciplinaria. Berna: Peter Lang.

Seco, M. (1991): “Introducción”. En Real Academia Española, Diccionario de la lengua castellana reducido a un tomo para su más fácil uso. Facsímil de la primera edición (1780). Madrid: Real Academia Española, pp. III-XII.

Terreros, E. (1767 [1786-1793]): Diccionario castellano con las voces de ciencias y artes, ed. facsímil, 4 vols., Madrid, Arco/Libros, 1987.

Terrón, N. (2019): "Historia de la lengua y lexicografía: el aumento de voces en la 6. a edición del Diccionario de la Academia (1822)". En Arnal, M. ${ }^{\text {a }}$ L. et alii (eds.). Actas del X Congreso Internacional de Historia de la Lengua Española. Zaragoza: Institución "Fernando el Católico", vol. II, pp. 1325-1341. 